\title{
Attitudes Towards Reference and Replaceability
}

\author{
Christopher Grau • Cynthia L. S. Pury
}

(C) Springer Science+Business Media Dordrecht 2013

\begin{abstract}
Robert Kraut has proposed an analogy between valuing a loved one as irreplaceable and the sort of "rigid" attachment that (according to Saul Kripke's account) occurs with the reference of proper names. We wanted to see if individuals with Kripkean intuitions were indeed more likely to value loved ones (and other persons and things) as irreplaceable. In this empirical study, 162 participants completed an online questionnaire asking them to consider how appropriate it would be to feel the same way about a perfect replica of a loved one, as well as other questions about replaceability. Participants who previously had endorsed Kripkean reference $(n=96)$ rated loved ones as less replaceable on two different measures than participants who had previously endorsed Descriptivist reference $(n=66, t(160) \geq 2.27$, $p \leq 0.02, \eta^{2} \geq 0.03$ ). Additional results suggest that this difference extends to other targets as well and is at least partially dependent on sentimental attachment.
\end{abstract}

\section{Introduction}

There has been a vigorous and important recent debate among empirically-minded philosophers over the possible cultural relativity of intuitions regarding linguistic reference. In a series of articles Machery et al. have suggested that East Asians are more inclined to hold "descriptivist" intuitions as opposed to "Kripkean" ones, while "Westerners" are said to hold Kripkean intuitions (Machery et al. 2004; Mallon et al. 2009). The results of such studies have been contested, and research continues on this topic. ${ }^{1}$ In this empirical study, we explore a connected topic that has thus far been neglected: the possible parallels between intuitions regarding the reference of proper names and those

\footnotetext{
${ }^{1}$ See Genone 2012 for a review, but see also Deutsch 2009, Jackman 2009, Lam 2010, Ludwig 2007 and Martí 2009. Machery and others have responded in various places, e.g. Machery et al. 2009, 2010 and Machery 2012. For a study which suggests the divide between Kripkeans and Descriptivists may not be so tidy, see Genone and Lombrozo (2012).

C. Grau $(\bowtie)$

Department of Philosophy \& Religion, Clemson University, Clemson, SC, USA

e-mail: grau@clemson.edu

C. L. S. Pury

Department of Psychology, Clemson University, Clemson, SC, USA

e-mail: cpury@clemson.edu
} 
regarding attachment in love. In other words, the goal is to explore possible parallels between an individual's views regarding the ways in which names attach to persons and that same individual's views regarding the proper focus of attachment in love. ${ }^{2}$

\subsection{Kraut's Analogy Between Love and Reference}

The impetus for such a study derives in part from the philosopher Robert Kraut's discussion of these issues in his 1986 essay "Love De Re". There Kraut considered the phenomenon of loving individual persons in an interesting and unexpected way: he draws a striking analogy between the referential behavior of linguistic terms and the attachment of a lover to the beloved. As several contemporary philosophers have noted, when we love an individual as an individual, we do not simply love the person's characteristics. Probably the most influential discussion of this issue comes from Nozick:

Apparently, love is an interesting instance of another relationship that is historical, in that (like justice) it depends upon what actually occurred. An adult may come to love another because of the other's characteristics; but it is the other person, and not the characteristics, that is loved. The love is not transferable to someone else with the same characteristics, even to one who "scores" higher for these characteristics. And the love endures through changes of the characteristics that gave rise to it. One loves the particular person one actually encountered. Why love is historical, attaching to persons in this way and not to characteristics, is an interesting and puzzling question. (1974, 167-68)

Our love seems crucially to involve a historic tie to the beloved, one that can survive a change in properties and is not necessarily proportional to any such change. The parallel here is with the way in which proper names refer to persons: the phenomenon of "rigid designation" made famous by Kripke involves the idea that a proper name "rigidly" attaches to an object in such a way that its reference does not switch or transfer to even an exactly similar object. Kraut explains the analogy:

The kind of "historical tie" of which Nozick speaks is precisely the kind of tie that holds between a proper name and its semantic referent (at least, according to several popular accounts of proper names). Once a name $\mathrm{n}$ comes to denote object o (and this might come about by virtue of o's having certain general characteristics), the name comes to be hooked up with o in a way that does not warrant the applicability ("transferability") of $n$ to some distinct though relevantly similar object $\mathrm{o}^{*}$. This is what rigid designation is all about. So we might say: a proper name is committed to its bearer, in much the way that a lover is historically committed to the object of his love. $(1986,424)$

The dominant theory for the reference of proper names (pre-Kripke) was what is known as a descriptivist theory. According to such a theory, what secures the reference of a proper name is the speaker's grasp of a description that uniquely picks out the object to which the name refers. In other words, I can successfully refer to "Saul Kripke" because I recognize him under the description "the philosopher who teaches at CUNY and authored Naming and

\footnotetext{
$\overline{2}$ The idea for this sort of study is mentioned briefly in Grau (2010) and the description of the study's purpose (section 1.1) is derived from the longer discussion in that article.
} 
Necessity", and this description does indeed uniquely pick him out: there is only one such person, and that person is in fact Saul Kripke. The apparently commonsense thought is that something like this must be going on in order for names to succeed in singular reference.

While this approach seems to work for many proper names, Kripke pointed out that there are many others for which it does not. His insight was that reference has a crucial historical or causal dimension. His (so-called) "causal theory of reference" was inspired in part by his realization that we "often use a name on the basis of considerable misinformation" (Kripke 1980, 84). While descriptivism claimed that reference presupposed some set of uniquely referring descriptive statements, we can think of many everyday cases where we have nothing close to the kind of knowledge required by such a condition. All I might know about Rod Blagojevich is that he is a dishonest politician, yet this is certainly not a unique description. Similarly, my only "knowledge" of Chubby Checker might be that he wrote "The Twist", but this is actually false. Yet in both these cases we would still want to claim that I successfully referred to the person in question. Kripke effectively demonstrated that a proper name refers to a person through the tracing of a particular historical path and not based on a particular cluster of descriptions that may or may not apply to the person in question.

The analogy with love should be clear at this point: just as the reference of a proper name is historical (depending on a past causal history) and does not refer to the person named in virtue of a description of his characteristics, one's love for another often has a historical (backward-looking) dimension and does not attach to a collection of properties but instead attaches to a singular person with a particular origin and causal history (what philosophers standardly refer to as a person's particular numerical identity). ${ }^{3}$ This analogy can be pushed even further: while descriptivism fails as an account of the reference of many proper names, it is plausible to view certain general terms as referring by virtue of descriptive content. The term 'stapler', for example, arguably refers to any object that matches the proper description of a stapler. Some general terms are accordingly nonhistorical in this respect (Kraut 1986, 425). Similarly, when the focus of my love is a property or a collection of properties rather than an individual person, presumably my love will (or at least should) extend to whatever person or thing has those properties.

One way, then, to determine the focus of one's love is to consider whether a different person who had the same properties would evoke the same attitudes as the beloved. If so, then this is evidence toward the conclusion that what one really loves is not the person as a singular individual but some aspects or properties of the person. Analogously, one way to determine whether a word is being used rigidly as a proper name or, instead, more like a general term (which functions along descriptivist lines) is to see if the user is committed to applying it to any object that meets a certain descriptive content, or if it is only applied to a particular historical object (or set of objects). Kraut sums up his discussion of the analogy between love and proper names as follows:

It is usually agreed that Lisa's history and origin are essential to her. If so, a name that uniquely refers to Lisa is not properly applicable to any possible object with a history and origin different from Lisa's. And, analogously, a love that is genuinely directed toward Lisa does not get directed toward any object with a history and origin different from hers. It is that that confers upon love the property of being

\footnotetext{
${ }^{3}$ Where numerical identity is standardly contrasted with qualitative identity. Two (or more) objects are qualitatively identical if they share all the same qualities, but an object can only be numerically identical ("one and the same object") with itself.
} 
directed toward Lisa. And it is that that makes love, at least love of individual persons, historical. $(1986,427)$

In the end, the analogy between the bonds of love and a theory of reference is perhaps not so surprising after all. When we use proper names to refer, we are attempting to pick out concrete individuals, and when we love someone as a particular person, our attachment is also to a concrete historical individual, that is, the beloved.

Kraut ends his essay by considering the relevance of this analogy to a proper analysis of love, and he concludes that the analogy helps to show that "irreplaceability or nonsubstitutivity" is the key notion to consider: he argues that counterfactuals involving replaceability help to show us the intentional focus of love and help us to determine whether a given love is genuinely historical (and rigid) or not (Kraut 1986, 427). Consider the theoretical possibility of a swap between a loved one and a qualitatively exact duplicate: one's response to such a case helps show whether one's bond is directed at a particular individual or not. Kraut wants to defend a vision of love in which resistance to such substitution can be legitimate. There are others, such as Derek Parfit, who disagree. Parfit, who in Reasons and Persons (1984), notoriously denied "the importance of identity" and with it the reasonableness of nonderivative self-concern, also denied that we have legitimate grounds for preferring the original loved ones over exact duplicates. Considering the fictional case of a woman named Mary Smith who creates a duplicate of herself using a replicating device, he says,

I fall in love with Mary Smith. How should I react after she has first used the Replicator? I claim both that I would and that I ought to love her Replica. This is not the "ought" of morality. On the best conception of the best kind of love, I ought to love this individual. She is fully psychologically continuous with the Mary Smith I loved, and she has an exactly similar body. If I do not love Mary Smith's Replica, this could only be for one of several bad reasons. (Parfit 1984, 295) ${ }^{4}$

Here we have something close to (what we might crudely call) a descriptivist conception of love rather than a conception of love as genuinely historical—on Parfit's account the actual history and identity of Mary Smith are both deemed intrinsically unimportant. This isn't to say that Parfit doesn't recognize our natural tendency to prefer the original; he just thinks we are ultimately irrational to place any significant weight on such a preference.

\subsection{Object Persistence and Psychological Essentialism}

These ideas find a parallel in prior work by psychologists on both object persistence and psychological essentialism. Regarding object persistence, the question of what makes an individual cat this particular cat (call him "Erwin") rather than a different cat turns out to involve both similarity of features and evidence of a causal chain from the original

\footnotetext{
${ }^{4}$ Note that this passage comes in a discussion of the legitimacy of attaching to "series-persons" rather than persons, and so Parfit's goal at that point is the more limited goal of defending such attachment. In the end, however, his position commits him to denying the importance of the identity of a loved one even in our world (and not just a world where series-persons are common), and with this the idea that resistance to replaceability is irrational. This is because Parfit argues (in Reasons and Persons) not just that identity does not matter, but that what does matter are psychological relations with any cause, and a duplicate possesses these psychological relations. (287) Parfit's position is discussed in greater detail in Grau (2010).
} 
observation until now, with the causal factors dominating when there is a conflict (Rips et al. 2006). Generally, an object must follow a logical spatiotemporal path from Place A at Time 1 to Place B at Time 2 to be denoted as the same; there is usually also persistence through property change, such as fruit ripening or people aging; and cohesion, or maintaining a cohesive boundary over time. It appears these intuitions regarding object identity have their source in a variety of psychological mechanisms, especially mechanisms for mid-level visual object processing (Scholl 2007).

Psychological essentialism proposes that people think about objects as if they have an inner "essence" that makes them what they are. Much of the psychology literature in this area examines the common and persistent tendency for thinkers to assume the existence of essential properties making a specific object an example of a more general category or natural kind (e.g., something that makes this particular animal a cat). Such natural kind essentialism runs deep: it is present in adults, young children (Gelman 2003), and perhaps even nonhuman primates (Phillips et al. 2010). Essences persist across surface changes, such as changes in appearance.

Gelman (2013) proposes that essentialism can be extended to even individual artifacts given the manner in which tracing the historical path of some valued artifacts (such as artworks) involves an appeal to the "non-obvious, hidden feature" of that object's causal history. Personal or historical events attached to an object (such as a treasured childhood toy or an authentic work of art) can imbue it with a special emotional status (Gelman 2013). When that happens, we trace the authenticity and ownership of an individual artifact through the object's causal history (with mere functional equivalence or surface similarity rejected as insufficient). Interestingly, these emotional responses appear to be at least somewhat resistant to boundary changes - if Hitler's sweater was unraveled and reknit into a new sweater, most people still do not want to wear it (Nemeroff and Rozin 1994). In this study we further examine attitudes of adults when presented with the possibility of replacement of entities to which they have a historical connection.

\subsection{Comparing Attitudes Regarding Reference and Replaceability}

As mentioned earlier, Machery et al. have suggested that individuals differ regarding the extent to which they are inclined to hold "descriptivist" intuitions as opposed to "Kripkean" intuitions regarding reference. Impressed by Kraut's analogy between love and reference, we were interested in whether individuals prone to Kripkean intuitions would have a similar "historical" attitude regarding attachment to individuals and objects. Similarly, we wondered whether those with more descriptivist intuitions regarding reference would correspondingly be less inclined to care about the numerical identity of persons and objects and more likely to "attach" to surface qualities.

We were also interested more generally in testing people's attitudes to replacement scenarios. (Such scenarios are discussed often in philosophy, but the intuitions of "the folk" are usually simply assumed.) In addition, we were interested in the relation between a person's resistance to the substitution of an object and their degree of emotional or sentimental attachment to that object. Finally, we wondered whether philosophical training and familiarity with rather unrealistic thought experiments would affect the degree to which participants were willing to accept hypothetical replacement scenarios. Accordingly, we set out to test the following hypotheses: 
Hypothesis 1: Participants who endorse a Kripkean, rather than a Descriptivist view of linguistic reference should report that it is less appropriate to feel the same way toward a replaced loved one.

Hypothesis 1a: Participants who endorse a Kripkean, rather than a Descriptivist view of linguistic reference should report decreased replaceability of other particular beings or things.

Hypothesis 2a: Overall, love should reduce replaceability. People (and possibly animals) whom one has a close emotional attachment to - such as a loved one or a pet — should be less replaceable than people one does not have a close attachment to - such as an acquaintance with whom one has a functional relationship.

Hypothesis 2b: Humans should be less replaceable than nonhumans..

Hypotheses 3 and 4: Other constructs that increase sentimentality should also make replacements less acceptable. First (Hypothesis 3), we directly manipulated sentimental attachment to an object by creating a between-participants condition in which a pair of shoes is a gift from a friend (High Sentimentality) compared to a favorite pair of shoes (Low Sentimentality). Shoes in the High Sentimentality condition should be rated as less replaceable than those in the Low Sentimentality condition. Second (Hypothesis 4), we measured individual differences in the belief that a pet is a member of the family. These beliefs should correlate with decreased replaceability of the pet.

Exploratory Hypothesis: Finally, because exact duplicates of living things are, at this time, impossible, individuals with greater exposure to the types of improbable thought experiments found in philosophy should have a greater acceptance of the basic premise of replacement of a living being with whom one has a relationship. Thus, amount of philosophy training might have a positive correlation with measures of human replicants having the same sense of relatedness to the participant that the original had.

\section{Experiment}

\subsection{Methods}

\subsubsection{Participants}

Participants were recruited through advertisements on philosophy blogs and websites, ads on general interest websites, and a paid experimental participation site (Amazon's "Mechanical Turk"), in conjunction with Yale University Cognitive Science's "Experiment Month" initiative.

Of the 237 participants who initiated the survey, 162 provided a complete set of answers. Of these, 81 were male, 79 were female, and 2 did not indicate gender. Mean age was $32.6(S D=11.5)$, with 1 participant (a Kripkean) not reporting age. Most 
participants reported US nationality, with 117 US nationals, 32 other nationals, and 13 with no nationality indicated; not surprisingly most (146) reported English as a first language, with 13 reporting another first language and 3 not indicating first language. Most were not professional philosophers: asked if they were a philosopher by occupation, 26 reported "yes", 136 "no". However, most did report at least some formal universitylevel training in philosophy; 37 reported a Bachelor's degree or current or completed graduate work in philosophy, 54 reported at least one university-level class in philosophy, 33 reported informal reading in philosophy, and 38 reported no training in philosophy.

Participants were randomly assigned to a High $(n=85)$ or Low $(n=77)$ Sentiment condition. Participants in the High Sentiment condition were older, $m=34.4, s d=11.7$, than those in the Low Sentiment condition, $m=30.7, s d=11.1, t(159)=2.03, p<0.04, \chi^{2}=0.03$. There were no other significant demographic differences between groups, all $p \mathrm{~s}>=0.17$.

All but two reported current or previous pet ownership.

\subsubsection{Materials and Procedures}

All participants completed an online survey, which contained the Kripkean/Descriptivist Classification measure, five replacement scenarios with follow-up questions, and finally demographic questions.

Kripkean/Descriptivist Classification Participants were classified as Kripkean or Descriptivist based on their answer to Machery et al.'s (2004) Gödel reference question (Machery et al. 2004, p. B6):

Suppose that John has learned in college that Gödel is the man who proved an important mathematical theorem, called the incompleteness of arithmetic. John is quite good at mathematics and he can give an accurate statement of the incompleteness theorem, which he attributes to Gödel as the discoverer. But this is the only thing that he has heard about Gödel. Now suppose that Gödel was not the author of this theorem. A man called "Schmidt" whose body was found in Vienna under mysterious circumstances many years ago, actually did the work in question. His friend Gödel somehow got hold of the manuscript and claimed credit for the work, which was thereafter attributed to Gödel. Thus he has been known as the man who proved the incompleteness of arithmetic. Most people who have heard the name 'Gödel' are like John; the claim that Gödel discovered the incompleteness theorem is the only thing they have ever heard about Gödel. When John uses the name 'Gödel', is he talking about:

(A) the person who really discovered the incompleteness of arithmetic? or

(B) the person who got hold of the manuscript and claimed credit for the work?

Answer A was classified as the Descriptivist answer, answer B as the Kripkean answer.

Replacement Targets Participants were then presented with replacement scenarios, each followed by questions about the replaceability of the target. For example, the first scenario (target: Shoes) asked participants to consider the following:

Suppose that it was possible to replace a pair of shoes with qualitatively-exact duplicates. This duplicate pair would be exactly similar in every way (any wear and 
tear on the shoes would be replicated in the new pair). Suppose also that you are informed that in 1 week your shoes will be replaced by such duplicates. (The original shoes will be destroyed).

All participants were presented with the Shoes target and four others. The second was also a pair of shoes, randomly assigned as either High or Low Sentiment (discussed below). The remaining scenarios, presented in the same way to all participants and in order of presentation, were: a pet you are very fond of (Pet), someone you love (Loved One), and someone you know but do not have a strong emotional connection to (for example, a waiter or cashier at a restaurant you visit regularly) (Acquaintance). In each of these, the target was described as having copies of the same memories and traits as the original, with the original being painlessly destroyed. Moreover, human replacements were described as believing they were the original person. The targets varied on being Beloved (Pet, Loved One) versus Functional (Shoes, Acquaintance), and Human (Loved One, Acquaintance) verses Nonhuman (Pet, Shoes).

Sentimental Attachment to Shoes Participants were randomly assigned to a High or Low Sentiment condition for the second scenario. In the High Sentiment condition, a second pair of shoes was described as a gift from a friend. In the Low Sentiment condition, a second pair of shoes was described as a favorite pair.

Sentimental Attitude About Pets Participants were asked to what extent they agreed that $a$ pet is like a member of the family. Responses were indicated on a 1 (Strongly Disagree) to 7 (Strongly Agree) scale.

Replaceability Following each scenario, two questions assessed philosophically different aspects of the replaceability of the target. The first, Descriptive Prediction, was assessed by the question How likely would you be to feel the same way about (target) as you felt about the original?, rated on a scale of 1 (Not at all Likely) to 7 (Extremely Likely). The second, Normative Appropriateness, was assessed by the question How appropriate would it be to feel the same way about this pair of shoes as you felt about the original pair?, rated on a scale of 1 (Not at all Appropriate) to 7 (Extremely Appropriate).

Duplicate's Psychological Replication Emotional replication was measured for the Pet, Loved One, and Acquaintance scenarios with the following item: How confident are you that this (pet or person) would think, feel, and act in the same way as the original (pet or person)? rated on a 1 (Not at all Confident) to 7 (Extremely Confident) scale.

Duplicate's Sense of Relatedness to the Participant Relationship replication was measured for Loved One and Acquaintance scenarios with parallel items to the Replaceability questions: Descriptive Prediction, asked as How likely would it be for this person to feel the same way about you that the original person felt? and Normative Appropriateness, asked as How appropriate would it be for this person to feel the same way about you that the original person felt? rated on the same scale.

Philosophy Training Level of training in Philosophy was coded as no training $=1$, informal reading only $=2$, one or more undergraduate classes but no degree $=3$, and $B A$ in Philosophy 
and any graduate work in Philosophy $=4$. Because philosophy training might result in different responses, we included it as a covariate in each major analysis (H1a, H2, H3, and H4).

Participants were also asked How confident are you that the replacement (target) are not, in fact, the original (target), but rather a different (target) with identical properties/attributes/characteristics? However, this question may confound numerical distinctness of the replicant with confidence in the fidelity of the replicant to the original. Thus, the item was not analyzed.

\section{Results}

Kripkean Versus Descriptivist Classification Overall, 96 participants (59\%) gave the Kripkean answer to the Gödel question, while 66 participants (41 \%) gave the Descriptivist answer. Gender did not differentiate between Kripkean and Descriptivist participants $\left(\chi^{2}=0.09, p>0.77\right)$, however Kripkeans were significantly older $(m=34.4, s d=11.9)$ than Descriptivists $\left(m=30.1, s d=10.5, t(159)=2.33, p<0.03, \eta^{2}=0.03\right)$. A Descriptivist answer was also marginally most likely among participants who had some college level philosophy training but were short of a degree or graduate study and those with no philosophy training. See Table 1.

There was no significant difference between Kripkeans and Descriptivists in Sentimental Attitude about Pets, $t(160)=1.02, p>0.3$.

Descriptivist Versus Kripkean Linguistic Reference Ratings of Likelihood and Normative Appropriateness of feeling the same way about a duplicate by Linguistic Reference are presented in Table 2. As predicted by Hypothesis 1 and shown in the first row, Kripkeans rated having the same feelings toward a replaced Loved One as significantly both less likely and less appropriate than Descriptivists. As predicted by Hypothesis 1a, parallel significant findings were found for replaced Pets, with nonsignificant trends in the predicted direction found for replaced Shoes and replaced Acquaintances.

To control for possible confounds, all analyses were rerun using Age and Philosophy training as covariates. The pattern of results remained identical: Kripkeans rated the emotional replaceability of a Loved One and a Pet as both less likely and less appropriate

Table 1 Kripkean verses descriptivism and amount of philosophy training

\begin{tabular}{llll}
\hline Philosophy training & Kripkean & Descriptivist & Totals \\
\hline None & $26(68 \%)$ & $12(32 \%)$ & 38 \\
Informal reading & $18(55 \%)$ & $15(45 \%)$ & 33 \\
One or more college course(s) & $26(48 \%)$ & $28(52 \%)$ & 54 \\
Degree or grad study & $26(70 \%)$ & $11(30 \%)$ & 37 \\
Totals & 96 & 66 &
\end{tabular}

$\chi^{2}=6.24, d f=3, p=0.10$ 
Table 2 Ratings by Descriptivists $(n=66)$ and Kripkeans $(n=96)$ of the liklihood and normative appropriateness of the participant feeling the same way about a duplicate

\begin{tabular}{|c|c|c|c|c|c|c|c|c|c|c|c|}
\hline \multirow[t]{2}{*}{ Duplicated target } & \multirow[t]{2}{*}{ Linguistic reference } & \multicolumn{5}{|c|}{ Likelihood rating } & \multicolumn{5}{|c|}{ Normative appropriateness rating } \\
\hline & & $m$ & $s d$ & $t(160)$ & $p$ & $\eta^{2}$ & $m$ & $s d$ & $t(160)$ & $p$ & $\eta^{2}$ \\
\hline \multirow[t]{2}{*}{ Loved One } & Descriptivist & 3.1 & 2.2 & 2.27 & 0.02 & 0.031 & 3.3 & 2.2 & 2.58 & 0.01 & 0.040 \\
\hline & Kripkean & 2.4 & 1.8 & & & & 2.5 & 2.0 & & & \\
\hline \multirow[t]{2}{*}{ Pet } & Descriptivist & 3.3 & 2.2 & 2.17 & 0.03 & 0.029 & 3.8 & 2.1 & 2.21 & 0.03 & 0.030 \\
\hline & Kripkean & 2.7 & 1.9 & & & & 3.0 & 2.1 & & & \\
\hline \multirow[t]{2}{*}{ Acquiantance } & Descriptivist & 4.7 & 1.9 & 1.03 & 0.31 & 0.007 & 4.4 & 2.1 & 1.25 & 0.21 & 0.010 \\
\hline & Kripkean & 4.3 & 2.0 & & & & 4.0 & 2.0 & & & \\
\hline \multirow[t]{2}{*}{ Shoes } & Descriptivist & 5.3 & 1.7 & 1.13 & 0.26 & 0.008 & 5.7 & 1.5 & 1.52 & 0.13 & 0.014 \\
\hline & Kripkean & 4.9 & 2.0 & & & & 5.3 & 1.9 & & & \\
\hline
\end{tabular}

than Descriptivists (minimum $F(1,157)=4.39, p<0.04, \eta^{2}=0.027$ ), with no significant difference in replaceability of Shoes or Acquaintances (all $F$ 's $<2.36$, all $\eta^{2}<0.015$ ).

Type of Replicant Effects of type of replicant and type of replaceability measured are presented in Fig. 1. They were tested by a 2 (Love for Replicant: Loved One and Pet versus Acquaintance and Shoes) $\times 2$ (Humanness of Replicant: Loved One and Acquaintance versus Pet and Shoes) $\times 2$ (Measure of Replaceability: Appropriateness versus Likelihood): repeated measures ANOVA. As predicted by Hypothesis 2a, Love had a strong effect on overall replaceability, $F(1,161)=243.80, p<0.001, \eta^{2}=0.299$, with Loved targets significantly less replaceable than Nonloved targets.

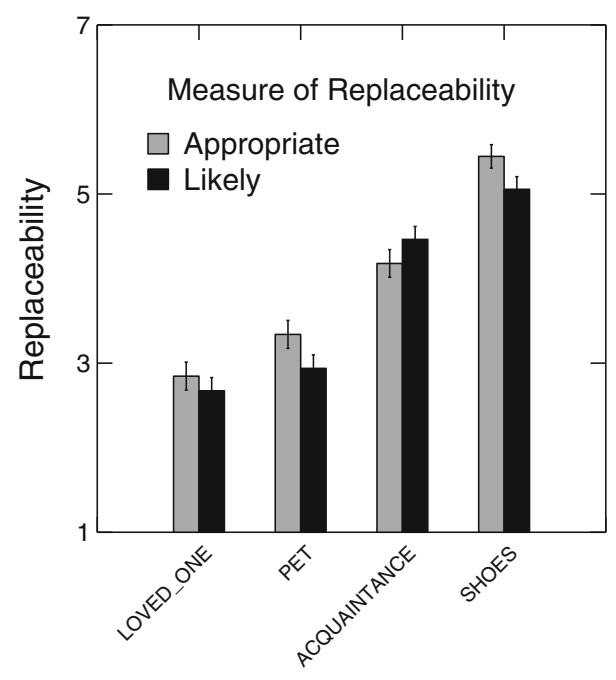

Type of Replicant

Fig. 1 Type of Replicant $\times$ Measure of Replaceability 
Humanity of target also had an effect: Human targets were rated as significantly less replaceable than nonhuman targets as predicted by Hypothesis $2 \mathrm{~b}, F(1,161)=28.97, p<0.001$, $\eta^{2}=0.038$.

All other effects and interactions were also significant and modified by small but significant triple interaction between Love for Replicant, Humanness of Replicant, and Measure of Replaceability, $F(1,161)=5.23, p<0.03, \eta^{2}=0.001$. As can be seen in Fig. 1, for Loved Ones, Pets, and Shoes, participants rated the Likelihood of feeling the same way about the replicant as significantly less likely than the appropriateness of doing so, minimum $t(161)=2.23$, $p<0.03, \eta^{2}=0.030$. This effect was reversed, however, for nonloved humans: participants rated the likelihood of their feeling the same way about replaced Acquaintances as significantly more likely than the appropriateness of feeling the same way, $t(161)=3.16$, $p<0.002, \eta^{2}=0.058$. Thus, for most types of replicants tested, participants thought they would be less likely to feel the same way than would be appropriate. However, for humans we have a functional but not loved relationship to, they thought they would be more likely to feel the same way than would be appropriate.

Including Linguistic Reference as a variable did not change the pattern of these effects nor did it have a significant interaction with any of them, maximum interaction $F(1,160)=2.40$, $p>0.12, \eta^{2}=0.001$.

Sentimentality Participants asked to imagine that a second pair of replaced shoes was a gift from a friend (High Sentiment) said it was marginally less Appropriate to feel the same way about the replacement $(m=4.5, s d=1.94)$ than participants asked to imagine that the pair was a their favorite pair (Low Sentiment, $m=5.1, s d=2.0, t(160)=1.84$, $p<0.067, \eta^{2}=0.020$ ). There was no significant effect of manipulated Sentiment on the Likelihood of feeling the same way, $t(160)=1.09, p>0.27, \eta^{2}=0.007$. Thus, only partial support for Hypothesis 3 was found.

Sentimentality, measured by belief that a pet is a member of the family, correlated negatively and significantly with both the Likelihood of feeling the same way towards a replaced pet, $r=-0.22, r^{2}=0.046$, and the Appropriateness of feeling the same way, $r=-0.21$, $r^{2}=0.042$. The more participants agreed that pets are family members, the less replaceable they reported a pet to be, thus Hypothesis 4 was supported.

Duplicate's Psychological Relatedness and Philosophy Training As tentatively predicted in the Exploratory Hypothesis, level of Philosophy Training was significantly and positive correlated with both a greater Likelihood and a greater Normative Appropriateness of human replicants feeling the same way about the participant as the original. See Table 3.

\section{Discussion}

Kraut's analogy between love and reference was presented in the context of discussions of ideal love and proper reference. We have found that "the folk" don't seem to all share the Kripkean intuitions that Kraut (and others) believe to be correct, and they also don't all share the same sort of resistance to substitution scenarios that Kraut suggest is the hallmark 
Table 3 Descriptive statistics and correlations with philosophy training of the liklihood and normative appropriateness of the duplicate feeling the same way about the participant as the original did

\begin{tabular}{lllllll}
\hline Target & Rating & $M$ & $S D$ & \multicolumn{2}{c}{ Correlation with philosophy training } \\
\cline { 5 - 7 } & & & & $r$ & $p$ & $r^{2}$ \\
\hline \multirow{2}{*}{ Loved one } & Likelihood & & & & \\
& Normative appropriateness & 3.72 & 2.25 & 0.18 & 0.02 & 0.031 \\
& Likelihood & 4.87 & 1.88 & 0.19 & 0.02 & 0.035 \\
& Normative appropriateness & 4.76 & 2.03 & 0.22 & 0.00 & 0.050 \\
\hline
\end{tabular}

of proper loving attachment. That the folk would not all end up Kripkeans did not surprise us: the prior studies of Machery and others have already shown that linguistic intuitions are more variable than either dogmatic Kripkeans or dogmatic Descriptivists might be inclined to admit. What this study has shown which is original and striking, however, is the statistically relevant tendency of those individuals with Kripkean linguistic intuitions to be more averse to replacement scenarios of all sorts than those with Descriptivist linguistic intuitions. While not everyone turns out to be either Kripkean in their views on reference or Krautian in their views on love and attachment, it does look like the Kripkeans out there are more likely to also be Krautian, just as the Descriptivists turn out to be more likely to share Parfitian intuitions regarding the reasonableness of replacement.

This strikes us as extremely interesting. One possibility is that the fact that Kripkeans find treating a replacement identically less appropriate than Descriptivists do suggests that Kripkeans/Krautians may have a more historical orientation generally: they may be individuals who are simply more committed to caring about the past in itself and to recognizing fundamentally backwards-looking considerations as primary. If this is right, then we predict they are probably less inclined than Descriptivists/Parfitians toward consequentialist ethical views (like Utilitarianism) due to the strictly forward-looking nature of those moral theories. ${ }^{5}$ There may be a basic difference in temperament here (among philosophers and "the folk") with some people prone to view the past as providing merely instrumentally useful knowledge and others giving the past a more fundamental role in their thoughts and concerns.

Beyond linguistic reference, love or sentimental attachment makes something less replaceable. Loved ones were less replaceable than pets; pets were less replaceable than acquaintances, and acquaintances were less replaceable than shoes. The more participants agreed that a pet was a member of the family, the less replaceable they rated the pet. Finally, shoes with a sentimental history were marginally less replaceable than shoes without a sentimental history. Again, there appears to be a basic concern with the causal history of the entity driving this phenomenon.

Participants also demonstrated a difference in their "hotter" expected emotional reaction to replacement and their "colder" judgment of how appropriate acceptance of the duplicate would be. In three of the four cases-loved ones, pets, and shoes -participants said they would feel even less OK with a replacement than would be appropriate. However,

\footnotetext{
${ }^{5}$ An anonymous referee has suggested a similar possible parallel with competing notions of function. In other words, it may be that Kripkeans/Krautians are also more drawn to historically-oriented accounts of function (like Wright's) while the Descriptivist/Parfitians may be more inclined towards ahistorical accounts (like that of Cummins). To the extent we are familiar with this literature (a bit!) we are inclined to agree.
} 
participants believed they would feel the same way towards a replaced acquaintance to a greater extent than would be appropriate. We think this might reflect a tendency to see such acquaintances in terms of their function rather than their inherent humanity. This may represent a mild form of Opotow's (1990) psychological distance: perceiving others as objects, and, in this research, thus as more replaceable. Objectively, we know that we should feel differently if the professor in our large lecture class was replaced with a duplicate, but we probably will not. Indeed, many of us may have had the experience of the replacement of a functional acquaintance, albeit not by an exact duplicate. Our mail carrier is out sick, our bus driver is fired, our nurse moves to another practice. Life goes on - that is, if we even notice.

One's historical connection to a functional acquaintance by definition lacks sentiment; thus we may have a lessened concern with the identity of such an individual. Future research might examine the effect of emotional salience on historical connection with respect to object persistence. For example, imagine removing components of an object bit by bit and replacing them with duplicate components. Can I replace more of an object and have it seem to be "the same" object if it is something I have a purely functional relationship to (say, an unread textbook) than if it is something I have a historical emotional connection to (say, a book given to me as a gift by my father)? (see Rips et al. 2006; Scholl 2007).

It would be worth exploring whether there is also a cultural variation here (similar to that studied by Machery). It would be remarkable if East Asian populations, for example, are typically more likely than "Westerner" populations to both be descriptivists and tend towards Parfitian intuitions regarding identity and replaceability (see also Nisbett et al. 2001). We hope that further research can explore this possibility.

We also hope that further studies can pursue the possible connections between the sort of historicity we have noticed among Kripkeans and the essentialist tendencies that Paul Bloom, Susan A. Gelman, and others have studied in children and adults (Bloom 1996, 2004, 2010; Gelman 2003, 2004, 2013). Are Kripkeans who are more bothered by replacement scenarios also more likely to be essentialists? We suspect they are, as we are sympathetic to Gelman's hypothesis that essentialist thinking has as its source several more basic cognitive tendencies, including a more fundamental domain-general capacity involving attention to causal history in tracking the identity of objects. ${ }^{6}$ Indeed, we see our results as providing further (indirect) support for this claim, as such a capacity would help explain why Kripkeans tend to place importance on causal history in both the domain of linguistic reference and in emotional attachment to objects, animals, and persons. However, so far as we know no work has yet been done exploring how and why these tendencies cluster in some individuals but not in others.

In short, we believe these findings are important and suggestive, and signal the need for more related empirical work to be pursued in order to better understand the deeper differences that may lay behind the diverse intuitions we see concerning reference, historicity, replaceability, and attachment.

\footnotetext{
${ }^{6}$ This point is made in Gelman 2003 but extended and elaborated in Gelman 2013. As she puts it in 2013: "I suggest that attention to object history is a domain-general capacity that serves as one of the foundations for psychological essentialism of animal kinds as well as concepts of individual artifacts." (no page number) In 2003 she makes a related suggestion with which we are also in sympathy: "There may be a link between tracking individual identity and kind essentialism in another way as well. That is, the sorts of objects for which we prefer to track individual identity (e.g. people, not paper clips) seem by and large to be the same sorts of objects we tend to essentialize. Perhaps the value places on certain entities initiates a process of individual identity-tracking, which then leads to hypothesizing that this sort of thing has unique and essential qualities." (319)
} 
Acknowledgments The authors would like to thank Yale University Cognitive Science's "Experiment Month" initiative and especially Mark Phelan for providing support for this study. We would also like to thank Paul Bloom, Roberto Casati, Joshua Knobe, Edouard Machery, Jonathan Phillips, Aaron Smuts, David Wasserman, Jen Cole Wright, and an anonymous referee for The Review of Philosophy and Psychology for helpful comments or suggestions on earlier drafts.

\section{References}

Bloom, Paul. 1996. Intention, history, and artifact concepts. Cognition 60: 1-29.

Bloom, Paul. 2004. Descartes' baby: How the science of child development explains what makes us human. New York: Basic Books.

Bloom, Paul. 2010. How pleasure works. New York: W.W. Norton \& Company.

Deutsch, Max. 2009. Experimental philosophy and the theory of reference. Mind \& Language 24: 445-466.

Gelman, Susan A. 2003. The essential child. New York: Oxford University Press.

Gelman, Susan A. 2004. Psychological essentialism in children. Trends in Cognitive Sciences 8(9): 404409. doi:10.1016/j.tics.2004.07.001.

Gelman, Susan A. 2013. Artifacts and essentialism. Review of Philosophy and Psychology. doi:10.1007/s13164013-0142-7.

Genone, James. 2012. Theories of reference and experimental philosophy. Philosophy Compass 7(2): 152-163.

Genone, James, and Tania Lombrozo. 2012. Concept possession, experimental semantics, and hybrid theories of reference. Philosophical Psychology 25(5): 1-26.

Grau, Christopher. 2010. Love and History. The Southern Journal of Philosophy 48(3): 246-271.

Jackman, Henry. 2009. Semantic intuitions, conceptual analysis, and cross-cultural variation. Philosophical Studies 146: 159-177.

Kraut, Robert. 1986. Love De Re. In Midwest studies in philosophy, vol. X, ed. Peter A. French, Theodore E. Uehling, and Howard K. Wettstein, 413-430. Minneapolis: University of Minnesota Press.

Kripke, Saul. 1980. Naming and necessity. Cambridge: Harvard University Press.

Lam, Barry. 2010. Are Cantonese speakers really descriptivists? Revisiting cross-cultural semantics. Cognition 115: 320-329.

Ludwig, Kirk. 2007. The epistemology of thought experiments: First-person approach vs. third-person approach. Midwest Studies in Philosophy 31: 128-159.

Machery, Edouard. 2012. Expertise and intuitions about reference. Theoria 73: 37-54.

Machery, Edoaurd, Ron Mallon, Shaun Nichols, and Stephen P. Stich. 2004. Semantics, cross-cultural style. Cognition 92: B1-B12.

Machery, Edouard, Christophe Olivola, and Molly de Blanc. 2009. Linguistic and metalinguistic intuitions in the philosophy of language. Analysis 69: 689-694.

Machery, Edouard, Max Deutsch, Ron Mallon, Shaun Nichols, Justin Sytsma, and Stephen P. Stich. 2010. Semantic intuitions: Reply to Lam. Cognition 117: 361-366.

Mallon, Ron, E. Machery, S. Nichols, and S. Stich. 2009. Against arguments from reference. Philosophy and Phenomenological Research 79(2): 332-356.

Martí, Genoveva. 2009. Against semantic multi-culturalism. Analysis 69: 42-48.

Nemeroff, C., and P. Rozin. 1994. The contagion concept in adult thinking in the United States: Transmission of germs and of interpersonal influence. Ethos 22(2): 158-186. doi:10.1525/eth.1994.22.2.02a00020.

Nisbett, Richard E., K. Peng, I. Choi, and A. Norenzayan. 2001. Culture and systems of thought: Holistic versus analytic cognition. Psychological Review 108: 291-310.

Nozick, Robert. 1974. Anarchy, state, and utopia. New York: Basic Books, Inc.

Opotow, Susan. 1990. Moral exclusion and injustice: An introduction. Journal of Social Issues 46(1): 1-20.

Parfit, Derek. 1984. Reasons and persons. New York: Oxford University Press.

Phillips, W., M. Shankar, and L.R. Santos. 2010. Essentialism in the absence of language? Evidence from rhesus monkeys (Macaca mulatta). Developmental Science 13(4): F1-F7. doi:10.1111/j.1467-7687.2010.00982.x.

Rips, L.J., S. Blok, and G. Newman. 2006. Tracing the identity of objects. Psychological Review 113(1): 1-30. doi:10.1037/0033-295x.113.1.1.

Scholl, Brian J. 2007. Object persistence in philosophy and psychology. Mind \& Language 22(5): 563-591. doi:10.1111/j.1468-0017.2007.00321.x. 